\title{
Supplementary materials for: \\ Influence of Water Saturation Level on Electrical Double Layer Properties in a Clay Mineral Mesopore: A Molecular Dynamics Study.
}

Sébastien Le Crom $^{1,2}$, Christophe Tournassat ${ }^{3,4}$, Jean-Charles Robinet ${ }^{2}$ and Virginie Marry ${ }^{1}$

1 Sorbonne Université, UPMC Univ Paris 06, UMR 8234, PHENIX, 4 place Jussieu, F-75005, Paris, France

2 Agence Nationale pour la Gestion des Déchets Radioactifs (ANDRA), Parc de la Croix Blanche rue Jean Monnet, F-92298,

Chatenay Malabry, France

${ }^{3}$ UMR 7327 Institut des Sciences de la Terre d'Orléans, Université d'Orléans-CNRS/INSU-BRGM, F-45071 Orléans, France

${ }^{4}$ Earth and Environmental Sciences Area, Energy Geosciences Division, Lawrence Berkeley National Laboratory, Berkeley, California 94720, United Stattes 

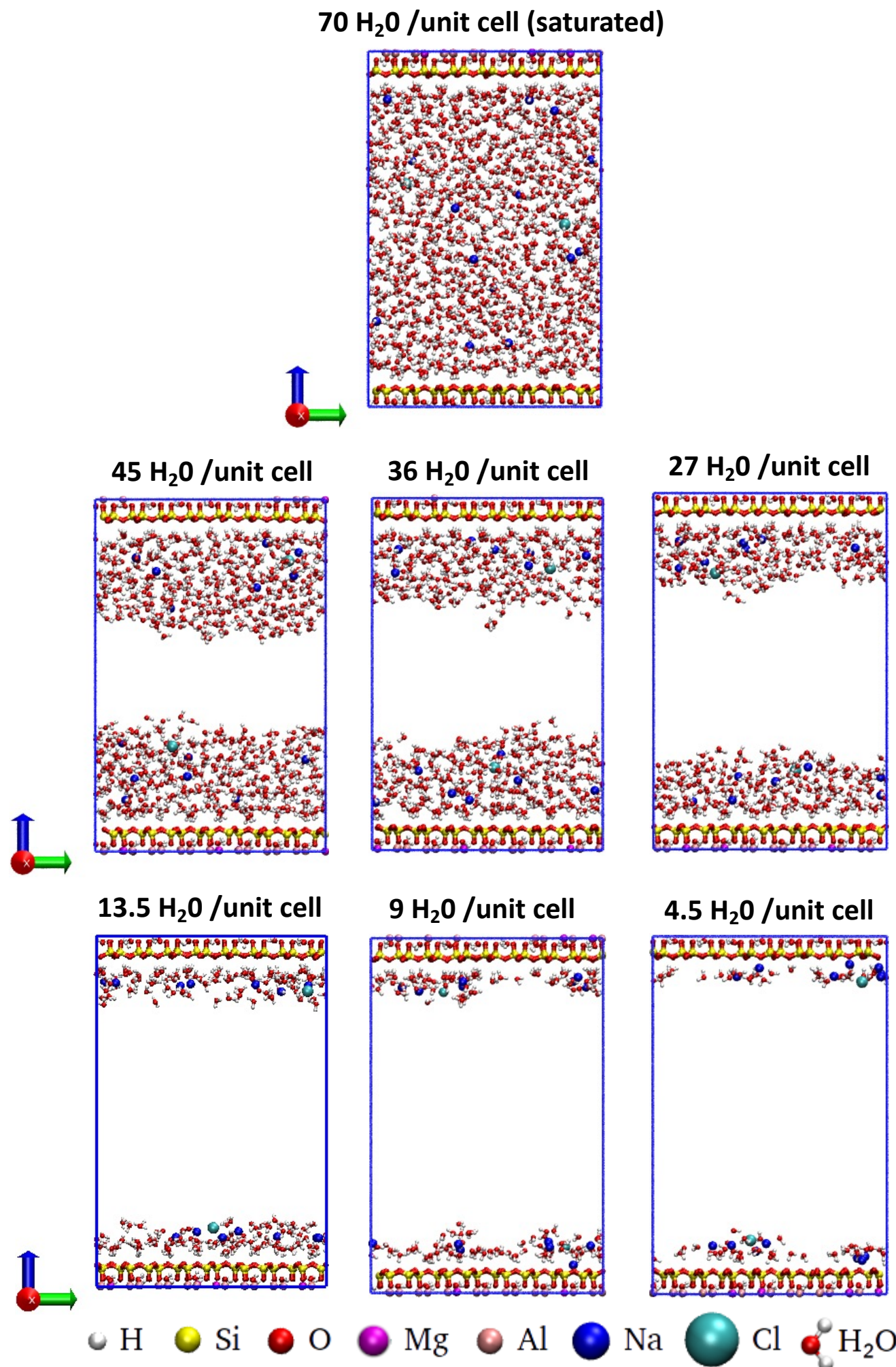

Figure S1: Snapshots of the $\mathrm{NaCl} /$ montmorillonite mesopore in different saturation conditions: saturated (top) and unsaturated (middle and bottom). The blue frame outlines the simulation unit box, which is periodically repeated in $\mathrm{x}, \mathrm{y}$ and $\mathrm{z}$ directions. The clay mineral layer is divided into two half-layers placed at each extremities of the simulation box in the $\mathrm{z}$ direction. Atom types are shown at the bottom of the figures. The white area in the center of the unsaturated pores corresponds to the gas phase. 
Forces $\left(\chi_{\mathrm{F}}^{2}\right)$ and dipoles $\left(\chi_{\mu}^{2}\right)$ error functions minimised during the PIM force field fitting procedure:

$$
\begin{gathered}
\chi_{\mu}^{2}=\frac{1}{\mathrm{~N}_{\text {conf. }}} \sum_{\text {conf. }}^{\mathrm{N}_{\text {conf. }}} \sum_{\text {atom }}^{N_{\text {atom. }}} \frac{\left\|\boldsymbol{\mu}_{\mathrm{MD}}-\boldsymbol{\mu}_{\mathrm{DFT}}\right\|^{2}}{\sum_{\text {atom }}\left\|\boldsymbol{F}_{\mathrm{DFT}}\right\|^{2}} \\
\chi_{\mathrm{F}}^{2}=\frac{1}{\mathrm{~N}_{\text {conf. }}} \sum_{\text {conf. }}^{\mathrm{N}_{\text {conf. }}} \sum_{\text {atom }}^{\mathrm{N}_{\text {atom. }}} \frac{\left\|\boldsymbol{F}_{\mathrm{MD}}-\boldsymbol{F}_{\mathrm{DFT}}\right\|^{2}}{\sum_{\text {atom }}\left\|\boldsymbol{F}_{\mathrm{DFT}}\right\|^{2}}
\end{gathered}
$$

with $\chi_{\mu}^{2}$ the error function on molecular dipoles, $\chi_{\mathrm{F}}^{2}$ the error function on forces, $\mathrm{N}_{\text {conf. }}$ the configurations (snapshots) number used during the fitting procedure, $N_{\text {atom. }}$ the number of molecules in each configuration, $\boldsymbol{\mu}_{\mathrm{MD}}$ the molecular dipoles computed by the classical force field, $\boldsymbol{\mu}_{\mathrm{DFT}}$ the molecular dipoles computed by DFT, $\boldsymbol{F}_{\mathrm{MD}}$ the forces computed by the classical force field, and $\boldsymbol{F}_{\text {DFT }}$ the forces computed by DFT. 


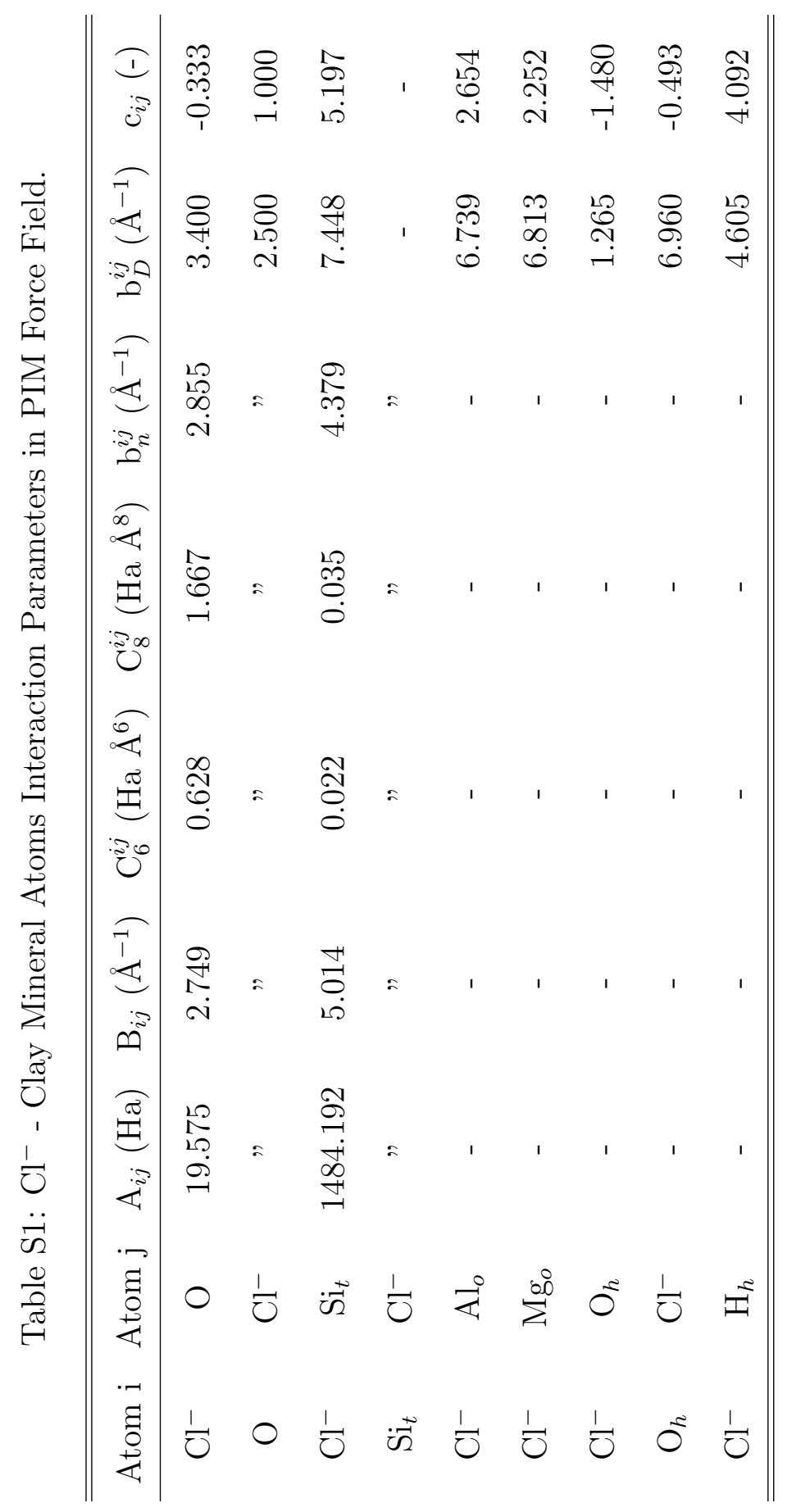




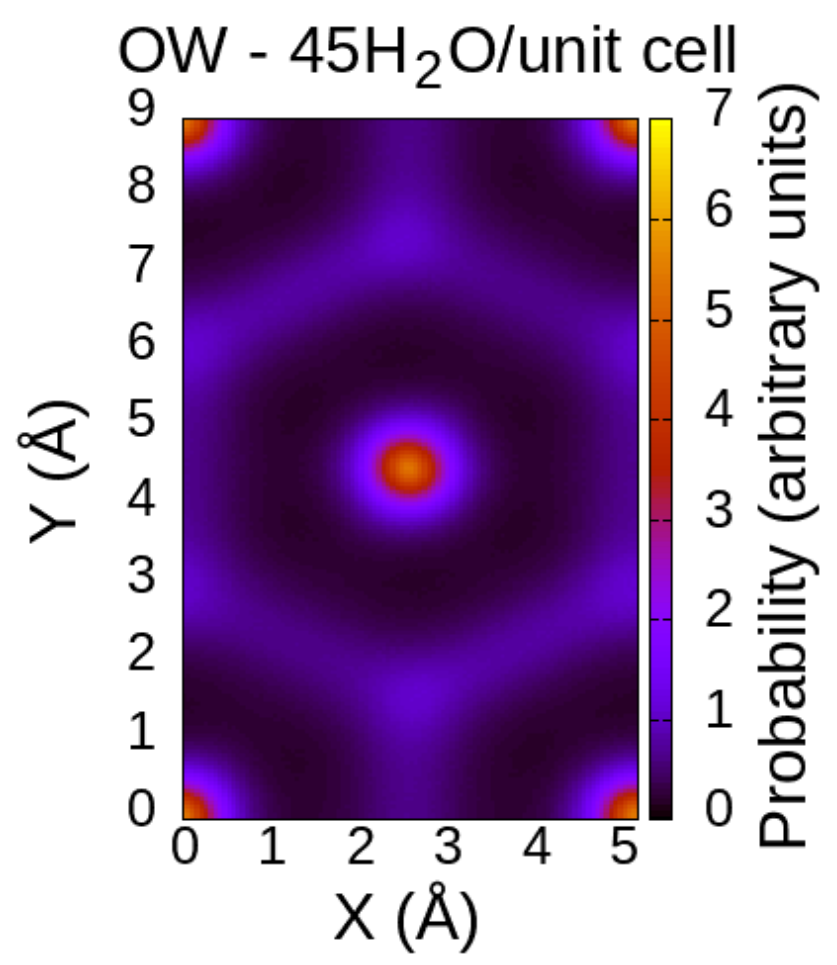

(a)

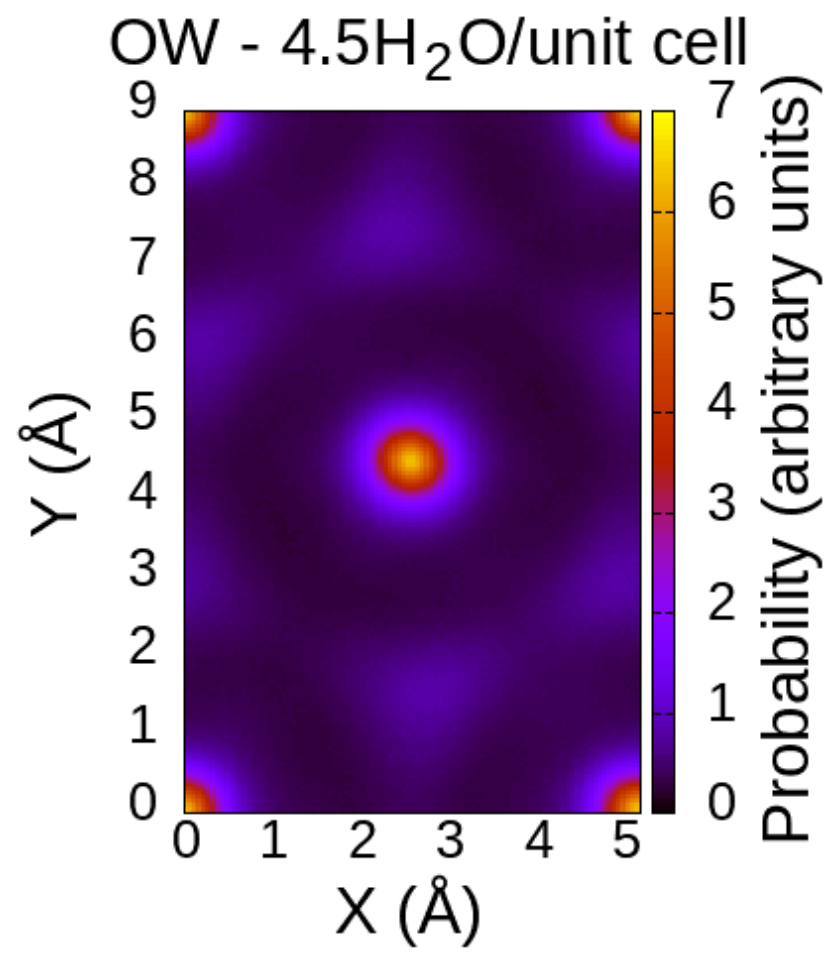

(b)

Figure S2: Atomic density maps of water oxygen atoms $(O W)$ in the first water layer averaged over a unit cell of the clay mineral surface: (a) pore with $45 \mathrm{H}_{2} \mathrm{O} /$ unit cell; (b) pore with $4.5 \mathrm{H}_{2} \mathrm{O} /$ unit cell. 


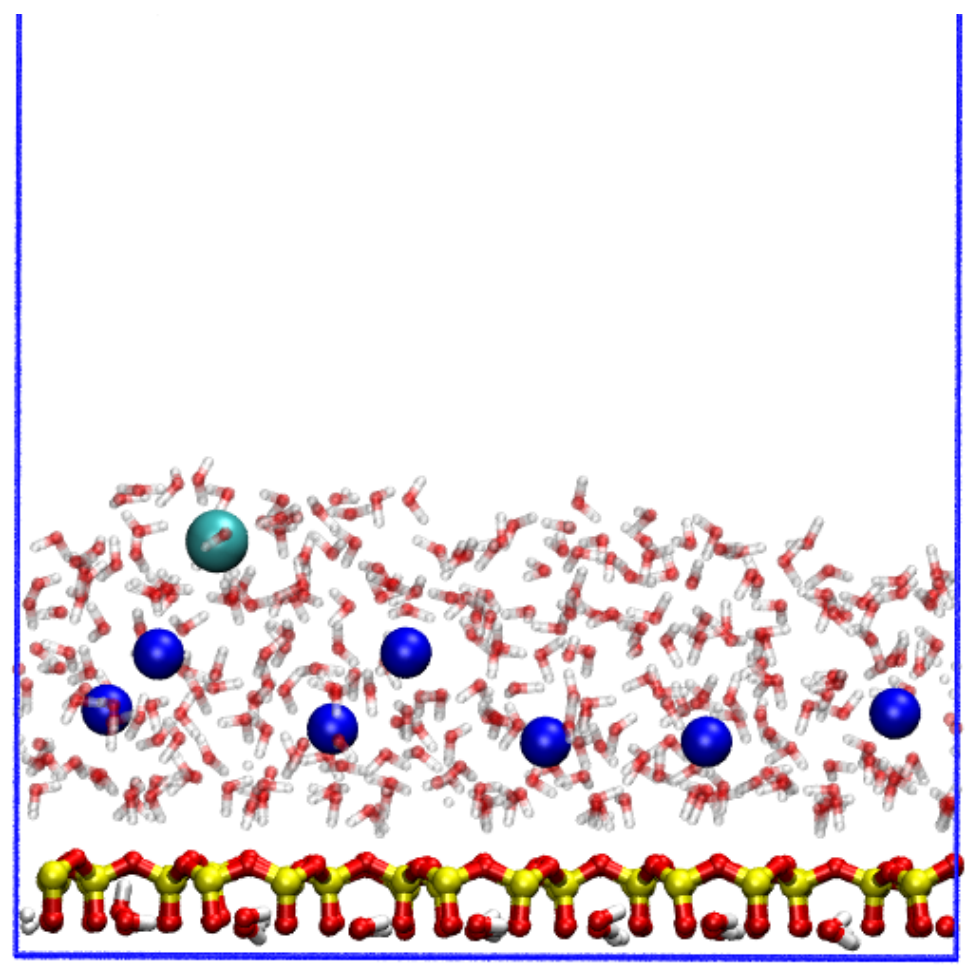

Figure S3: Snapshot of half a pore $\left(36 \mathrm{H}_{2} \mathrm{O}\right.$ system $)$ with focus on ionic distributions: $\mathrm{Na}^{+}$ (blue) and $\mathrm{Cl}^{-}$(cyan). 
Table S2: Position and Number of OW in the First Peak of the Radial Distribution Functions of OW Water Atoms Around $\mathrm{Na}^{+}$as Function of Pore Saturation.

\begin{tabular}{ccc}
\hline \hline $\mathrm{N}_{H_{2} O} /$ unit cell & $\mathrm{g}_{N a^{+}-O W}(\mathrm{r}) 1^{\text {st }}$ peak position $(\AA)$ & $\mathrm{n}_{O W}\left(1^{\text {st }}\right.$ peak $)$ \\
\hline Saturated & 2.40 & 5.820 \\
45 & 2.40 & 5.781 \\
36 & 2.40 & 5.757 \\
27 & 2.40 & 5.702 \\
13.5 & 2.39 & 5.167 \\
9 & 2.37 & 4.424 \\
4.5 & 2.37 & 3.157 \\
\hline \hline
\end{tabular}

Table S3: $\mathrm{Na}^{+}$First Shell Coordination Composition. OW Corresponds the Water Oxygen Atoms, Os Corresponds the Clay Mineral Surface Oxygen Atoms.

\begin{tabular}{ccc}
\hline \hline $\mathrm{Na}^{+}$region & $\mathrm{n}_{O W}$ & $\mathrm{n}_{O s}$ \\
\hline $0_{\text {inner-sphere }} 1^{\text {st }}$ peak & 2.10 & 5.70 \\
$0_{\text {inner-sphere }} 2^{\text {nd }}$ peak & 3.71 & 0.66 \\
All outer-shpere & 5.83 & - \\
\hline \hline
\end{tabular}




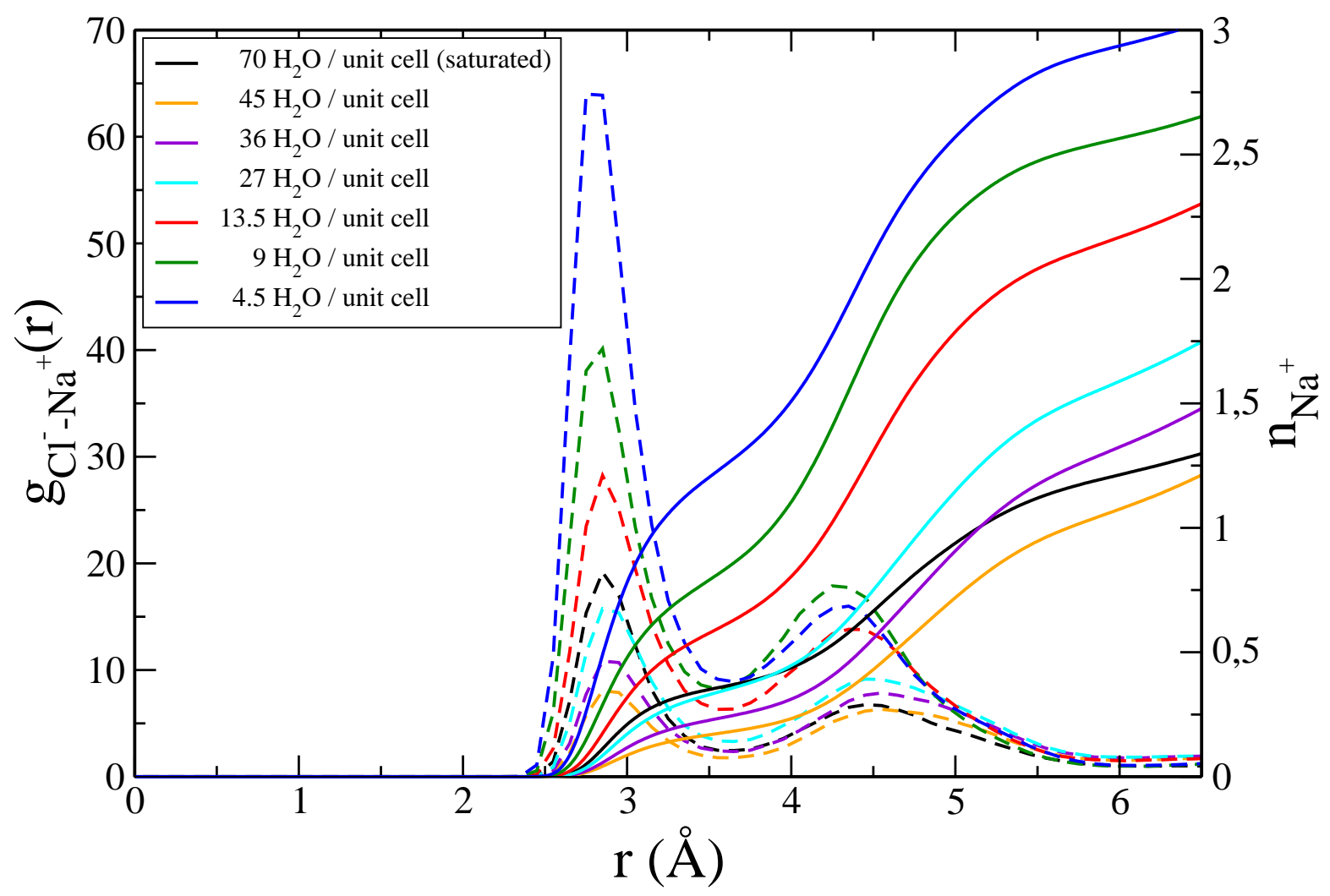

Figure S4: Radial distribution functions (dashed lines) and integrals (solid lines) of $\mathrm{Na}^{+}$ around $\mathrm{Cl}^{-}$as a function of pore saturation. The left y-axis corresponds to the radial distribution functions and the right y-axis corresponds to the integrals.

Table S4: Position and Number of $\mathrm{Na}^{+}$in the First Peak of the Radial Distribution Functions of $\mathrm{Na}^{+}$Around $\mathrm{Cl}^{-}$as a Function of Pore Saturation.

\begin{tabular}{|c|c|c|}
\hline $\mathrm{N}_{\mathrm{H}_{2} \mathrm{O}} /$ unit cell & $\mathrm{g}_{C l^{-}-N a^{+}}(\mathrm{r}) 1^{\text {st }}$ peak position $(\AA)$ & $\mathrm{n}_{\mathrm{Na}^{+}}\left(1^{\text {st }}\right.$ peak $)$ \\
\hline Saturated & 2.85 & 0.370 \\
\hline 45 & 2.89 & 0.183 \\
\hline 36 & 2.89 & 0.246 \\
\hline 27 & 2.88 & 0.357 \\
\hline 13.5 & 2.85 & 0.606 \\
\hline 9 & 2.82 & 0.804 \\
\hline 4.5 & 2.79 & 1.271 \\
\hline
\end{tabular}




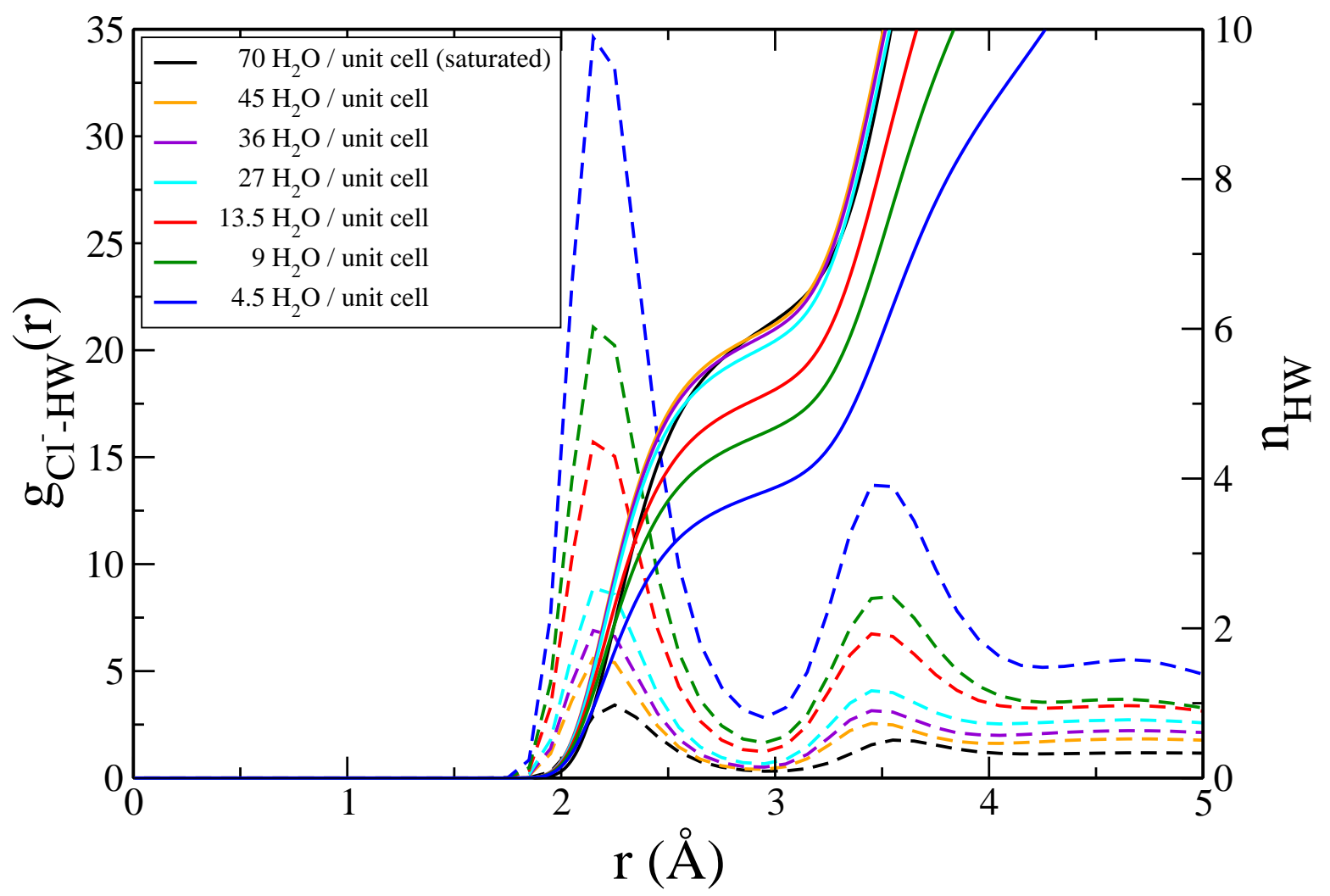

Figure S5: Radial distribution functions (dashed lines) and integrals (solid lines) of HW water atoms around $\mathrm{Cl}^{-}$as a function of pore saturation. The left y-axis corresponds to the radial distribution functions and the right $\mathrm{y}$-axis corresponds to the integrals.

Table S5: Position and Number of HW Atoms in the First Peak of the Radial Distribution Functions of Water Molecules Around $\mathrm{Cl}^{-}$as a Function of Pore Saturation.

\begin{tabular}{ccc}
\hline \hline $\mathrm{N}_{H_{2} O} /$ unit cell & $\mathrm{g}_{C l^{-}-H W}(\mathrm{r}) 1^{\text {st }}$ peak position $(\AA)$ & $\mathrm{n}_{H W}\left(1^{\text {st }}\right.$ peak $)$ \\
\hline Saturated & 2.24 & 11.314 \\
45 & 2.18 & 10.680 \\
36 & 2.18 & 10.573 \\
27 & 2.18 & 10.253 \\
13.5 & 2.18 & 8.140 \\
9 & 2.18 & 6.728 \\
4.5 & 2.18 & 5.300 \\
\hline \hline
\end{tabular}




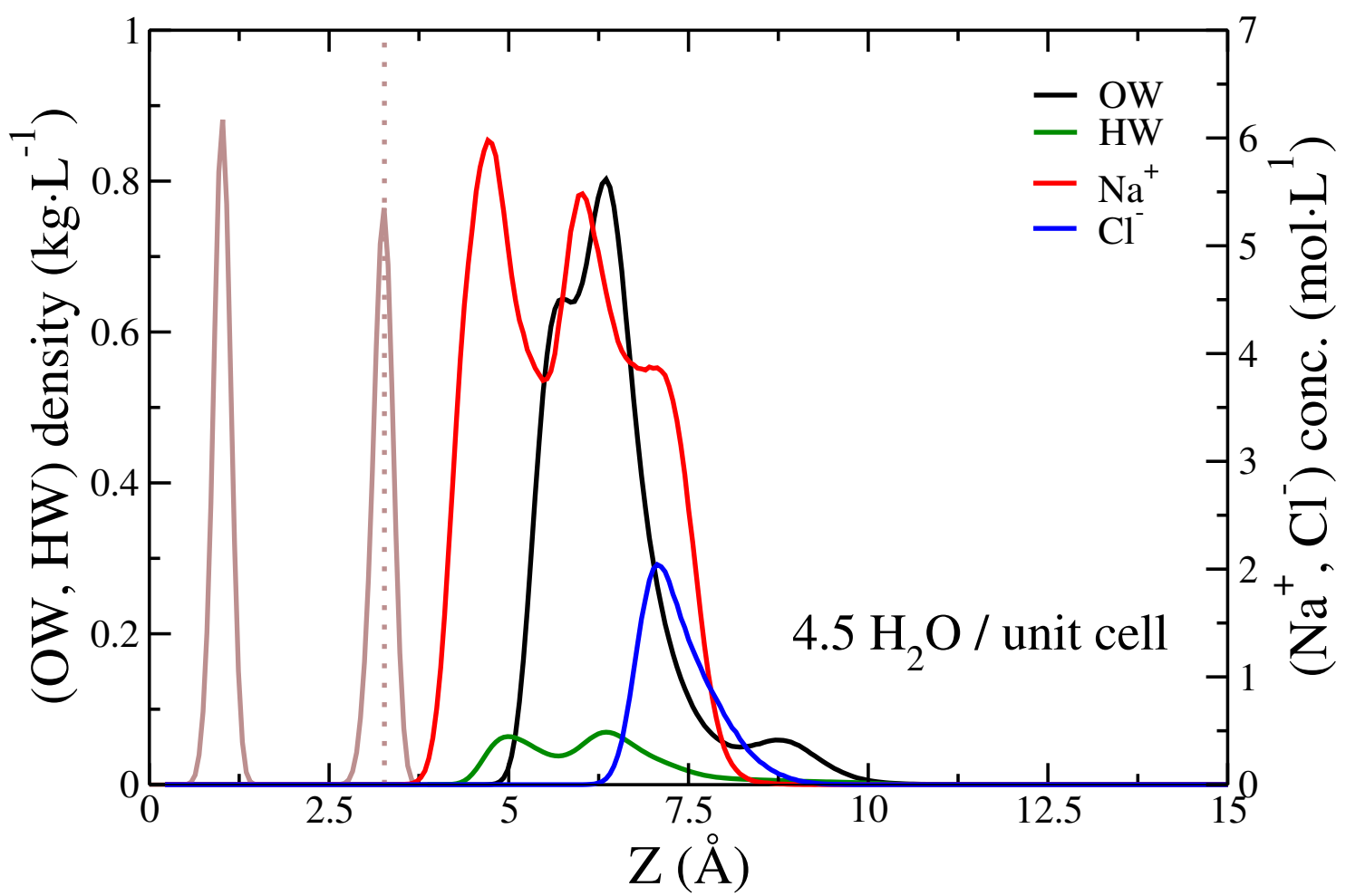

(a)

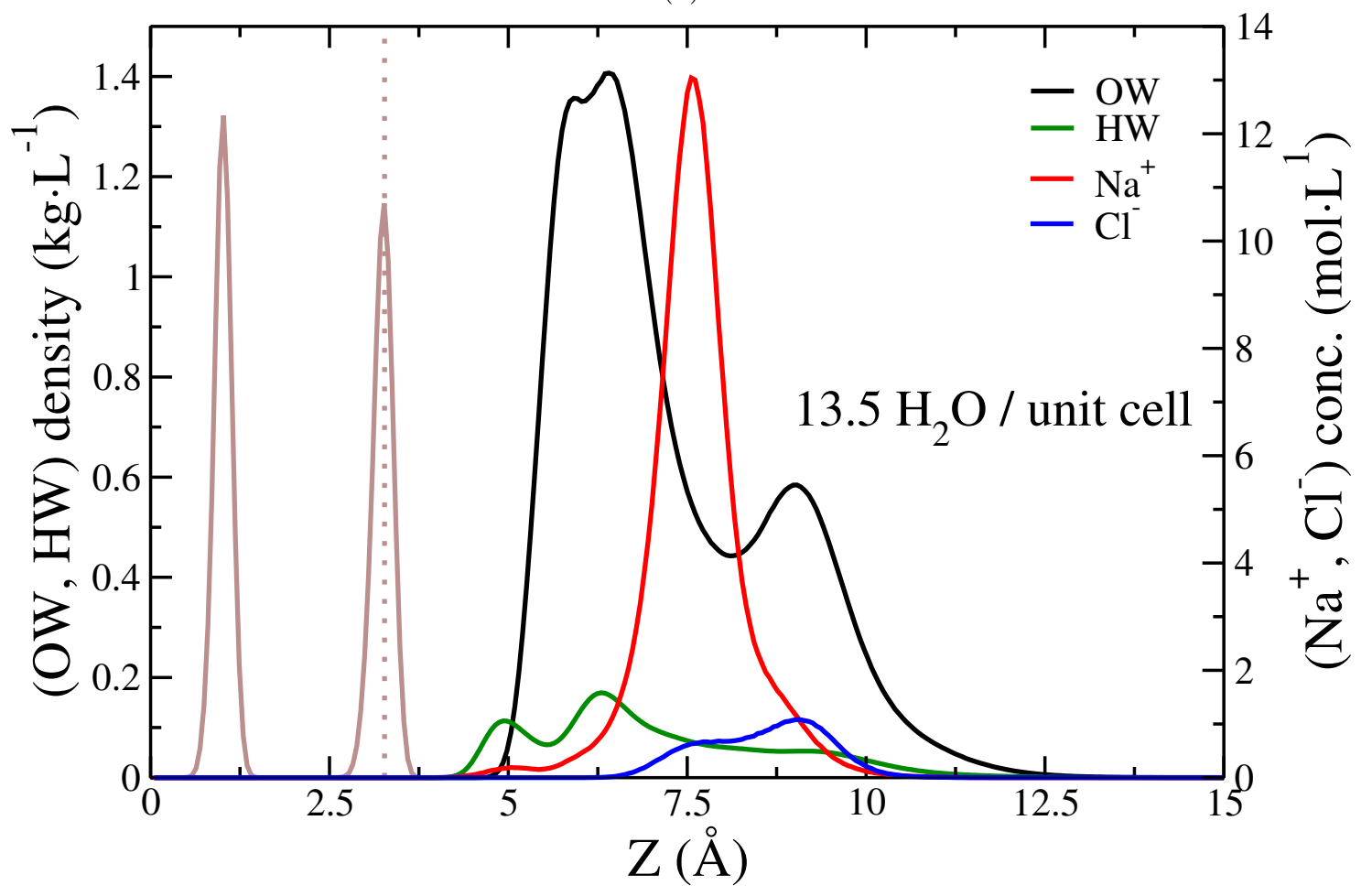

(b)

Figure S6: Water atoms and ions distribution profiles normal to clay mineral for the (a) 4.5 $\mathrm{H}_{2} \mathrm{O}$ per unit cell system and (b) $13.5 \mathrm{H}_{2} \mathrm{O}$ per unit cell system. Clay mineral layer oxygen distributions are shown in brown, and the center of mass of surface oxygens is represented by a brown dotted line at $\mathrm{z}=3.27 \AA$. The left $\mathrm{y}$-axis corresponds to the water atoms density profiles and the right $\mathrm{y}$-axis corresponds to the ions concentration profiles. 


\section{Nonpolarizable force field simulations}

\subsection{Systems and simulation details}

Simulations using nonpolarizable force fields were run with the LAMMPS Molecular Dynamics package. The ClayFF force field was used for atoms in clay mineral layers, together with the SPC/E water model. Periodic boundary conditions were used in all directions. The cutoff radius for short-range electrostatic and repulsion-dispersion interactions was set to $10 \AA$.The long-range electrostatic interactions were computed using the Particle-Particle-Particle-Mesh solver with a precision of $10^{-} 4$. The SHAKE algorithm was used to keep the water molecules rigid.

Unsaturated systems were first equilibrated for $20 \mathrm{~ns}$ in the $N V T$ ensemble at $300 \mathrm{~K}$ using a Nosé-Hoover thermostat, gradually increasing the timestep from 0.1 fs to 1.0 fs and the thermostat constant from 10 fs to 1000 fs. The total simulation time of the production phases for the unsaturated pores simulated with ClayFF was set to 100 ns in the NVT ensemble at $300 \mathrm{~K}$ with a thermostat constant of $1000 \mathrm{fs}$ and with a timestep of $1.0 \mathrm{fs}$. Surface charge compensation values in Figure S7 were averaged on the whole trajectories.

Table S6 summarizes the main characteristics of the different systems, namely the number of water molecules per unit cell as well as the added $\mathrm{NaCl}$ concentration. 
Table S6: Description of the Systems Simulated with the Nonpolarizable ClayFF Force Field: Ratio Between the Number of Water Molecules and the Clay Mineral Layer Unit Cells Number and the Concentration of $\mathrm{NaCl}$ Salt in the Aqueous Phase. These Systems are Twice as Concentrated in $\mathrm{NaCl}$ Salt Compared to Those Shown in the Main Body of the Paper (Simulated with the PIM Polarizable Force Field).

\begin{tabular}{cc}
\hline \hline $\mathrm{N}_{\mathrm{H}_{2} \mathrm{O}} /$ unit cell & $\mathrm{c}_{\mathrm{NaCl}}\left(\mathrm{mol} \mathrm{L}^{-1}\right)$ \\
\hline Saturated & 0.10 \\
45 & 0.38 \\
36 & 0.48 \\
27 & 0.64 \\
13.5 & 1.27 \\
9 & 1.91 \\
4.5 & 3.82 \\
\hline \hline
\end{tabular}

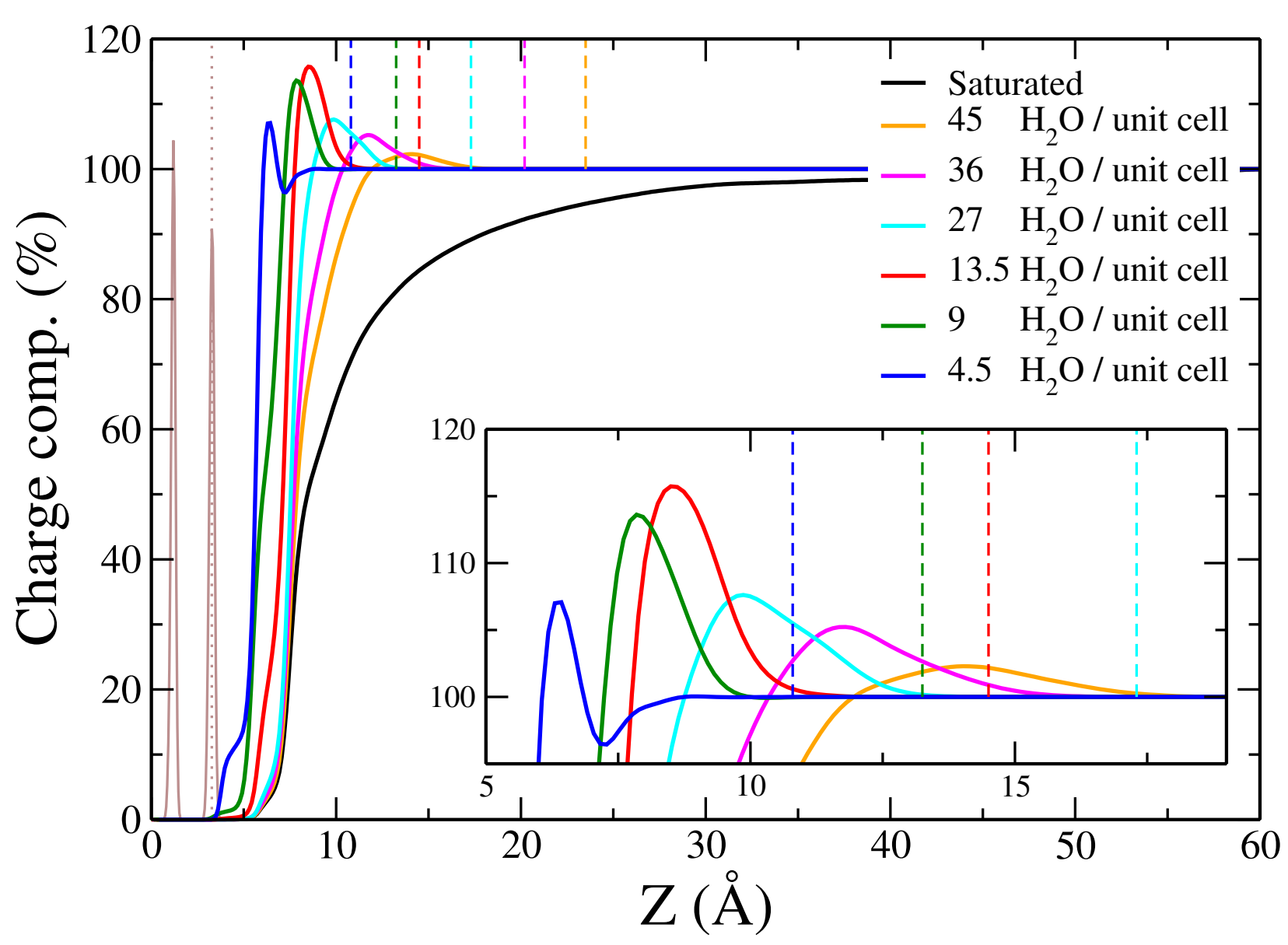

Figure S7: Clay mineral charge compensation distribution profiles in the direction normal to the clay mineral surface as a function of pore saturation for systems simulated with the nonpolarizable ClayFF force field. These systems are twice as concentrated in $\mathrm{NaCl}$ salt compared to those shown in the main body of the paper (simulated with the PIM polarizable force field). 


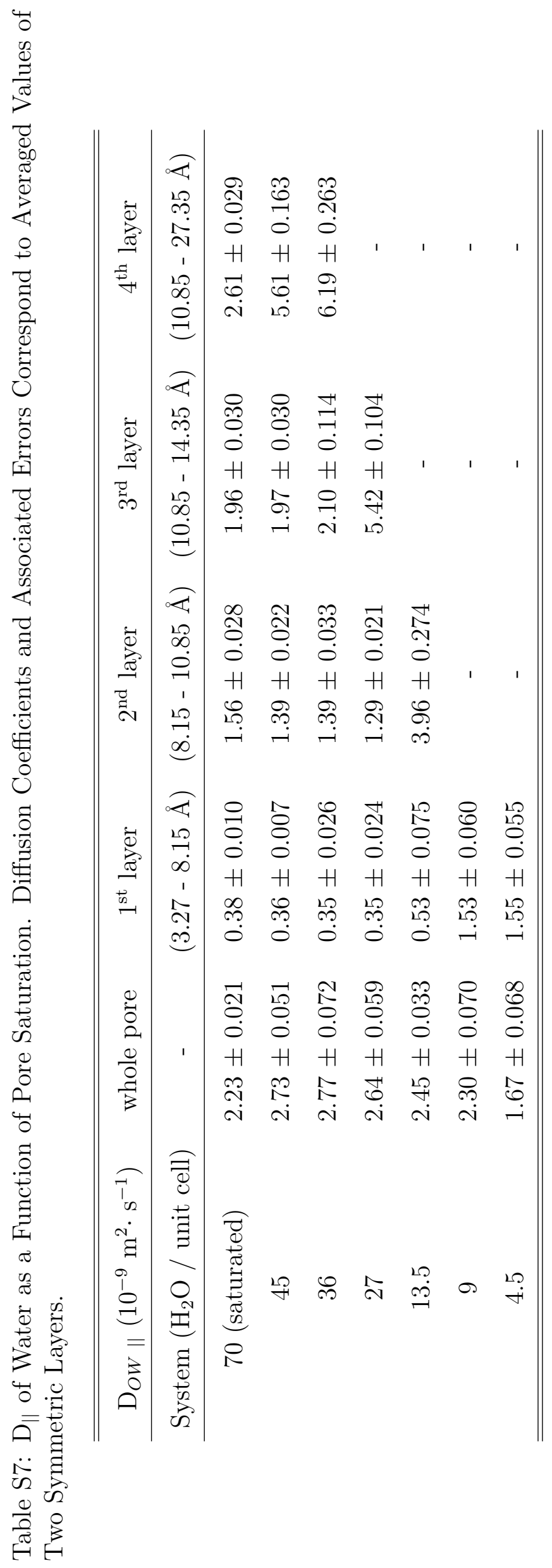




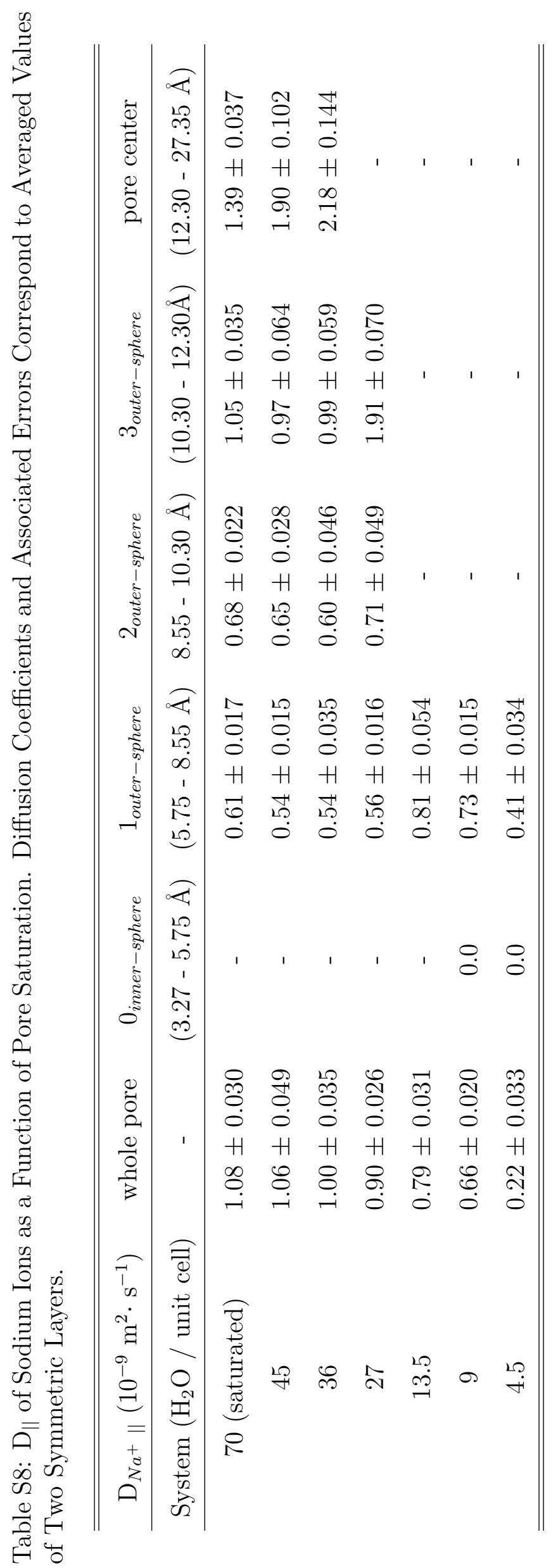


Table S9: $\mathrm{D}_{\|}$of Chloride Ions as a Function of Pore Saturation.

\begin{tabular}{cc}
\hline \hline $\mathrm{D}_{C l^{-}} \|\left(10^{-9} \mathrm{~m}^{2} \cdot \mathrm{s}^{-1}\right)$ & whole pore \\
System $\left(\mathrm{H}_{2} \mathrm{O} /\right.$ unit cell $)$ & - \\
\hline 70 (saturated) & $1.55 \pm 0.058$ \\
45 & $1.57 \pm 0.072$ \\
36 & $1.51 \pm 0.026$ \\
27 & $1.30 \pm 0.065$ \\
13.5 & $0.97 \pm 0.059$ \\
9 & $0.58 \pm 0.044$ \\
4.5 & $0.26 \pm 0.042$ \\
\hline \hline
\end{tabular}




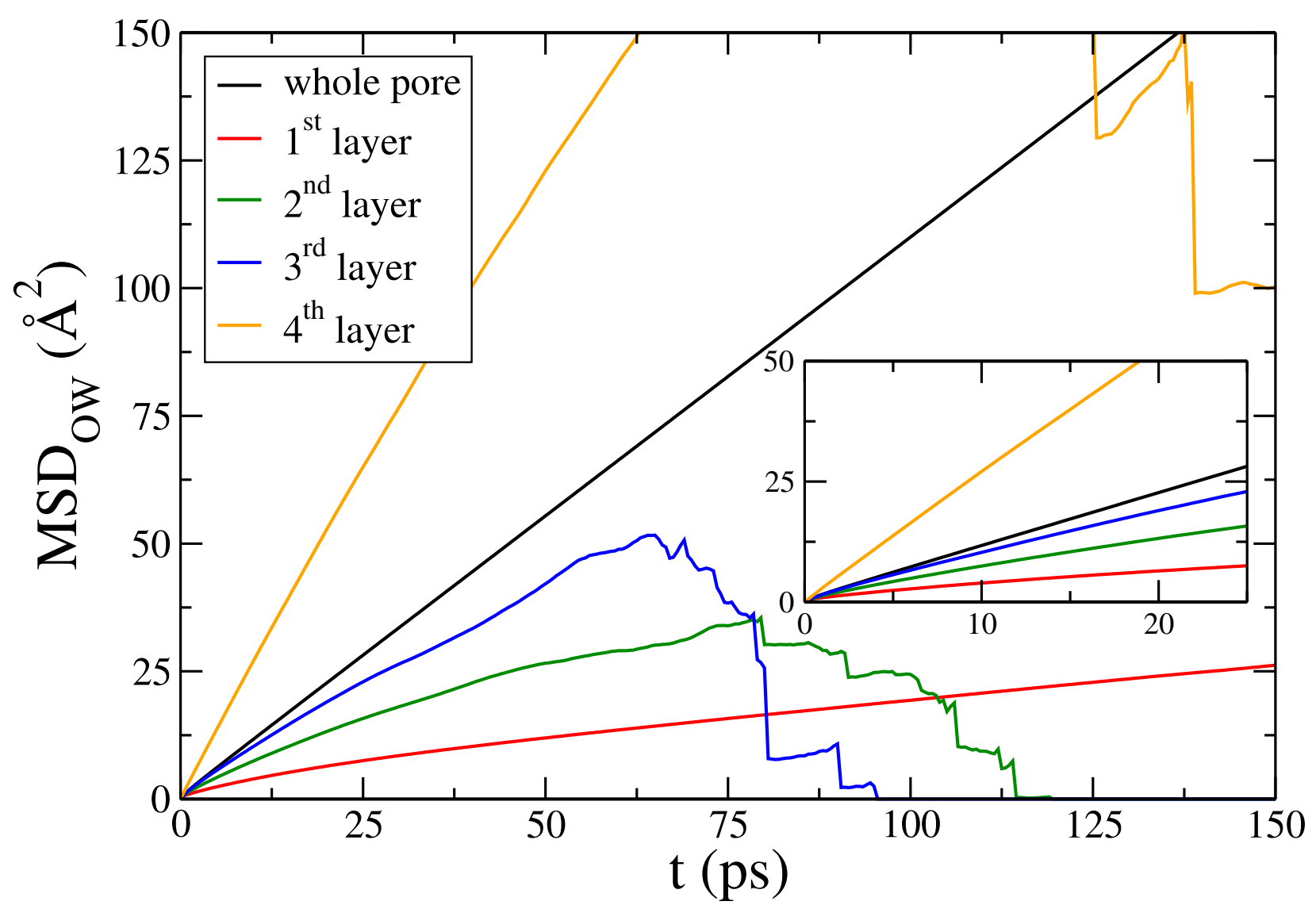

Figure S8: Mean square displacement (MSD) of water molecules as a function of time and as a function of distance from clay mineral surface (system: pore with $36 \mathrm{H}_{2} \mathrm{O}$ / unit cell). 